\title{
Atrial Fibrillation in the Arab World: A Bibliometric Analysis of Research Activity from 2004 to 2019
}

\author{
Dany Akiki ${ }^{1, *}$, Said El Hage ${ }^{1,2}$, Elias Wakim ${ }^{1}$, Steven Safi ${ }^{1}$, Elise Assouad ${ }^{3}$, Pascale Salameh ${ }^{1,4,5,6}$
}

\section{ORCID IDs}

Akiki D (D) https://orcid.org/0000-0001-8365-5958

El Hage S (D) https://orcid.org/0000-0001-9475-6746

Wakim E (D) https://orcid.org/0000-0003-3951-8336

\author{
Safi S (D) https://orcid.org/0000-0002-7634-8439 \\ Assouad E (D) https://orcid.org/0000-0001-8930-4104 \\ Salameh P (D) https://orcid.org/0000-0002-4780-0772
}

\begin{abstract}
Background: Atrial fibrillation (AF) is in an increasing pattern worldwide, especially in the Arab world. Objective: The aim of this article is to assess AF research activity in the Arab countries over the past 16 years, taking into consideration the population size, gross domestic product (GDP) and disability-adjusted life years (DALY). Methods: Atrial fibrillation related research articles published from Arab countries between 2004 and 2019 were collected from the MEDLINE database and are cited online on PubMed. Medical Subject Heading (MeSH) terms related to the subject, the origin and the date of publication were used to search for the published articles. Results: The number of AF related publications in the Arab world over the past 16 years was only $283(0.73 \%)$ out of a total of 38,983 publications worldwide. Saudi Arabia ranked first in terms of number of AF related publications, followed by Egypt. Lebanon is the country with the highest number of publications per USD billion GDP, while Egypt and Saudi Arabia have the highest number of publications per 1\% DALYs. According to the population size, Qatar and Bahrain produced the highest number of publications per million persons (PPMP). A strong and positive correlation was found between the number of publications and the GDP. The population size and the percentage of DALY showed positive yet weak correlation. Conclusion: A slight increase in AF related publications is observed. Nonetheless, AF research activity in the Arab world is still insufficient.
\end{abstract}

KEYWORDS: Atrial fibrillation; Bibliometrics; Middle East; Cardiology.

1. Lebanese University - Faculty of Medical Sciences -Department of Internal Medicine - Hadath - Lebanon.

2. Lebanese University - Faculty of Medical Sciences - Neuroscience Research Center - Hadath - Lebanon.

3. Lebanese American University - School of Arts and Science - Department of Medicine - Byblos - Lebanon.

4. Lebanese University - Faculty of Pharmacy - Department of Basic Science - Hadath - Lebanon.

5. University of Nicosia - Medical School - Department of Primary Care and Population Health - Nicosia - Cyprus

6. Institut National de Santé Publique - Epidémiologie Clinique et Toxicologie - Sector of Public Health and Epidemiology - Beirut - Lebanon.

*Corresponding author: danyakiki@live.com

Received: Nov 21, 2020 | Accepted: Feb 22, 2021 


\section{INTRODUCTION}

The Arab world consists of 22 countries, members of the League of Arab States located in the Middle East and North Africa. Bahrain, Iraq, Jordan, Kuwait, Lebanon, Oman, Palestine, Qatar, Saudi Arabia, Syria, the United Arab Emirates and Yemen are located in the Middle East. Algeria, Comoros, Djibouti, Libya, Mauritania, Morocco, Sudan, Somalia and Tunisia are located in North Africa. Egypt is the only country located in both these regions.

Cardiovascular diseases (CVDs) are the leading cause of death worldwide. This is also the case of the Arab world (Fig. 1)1.

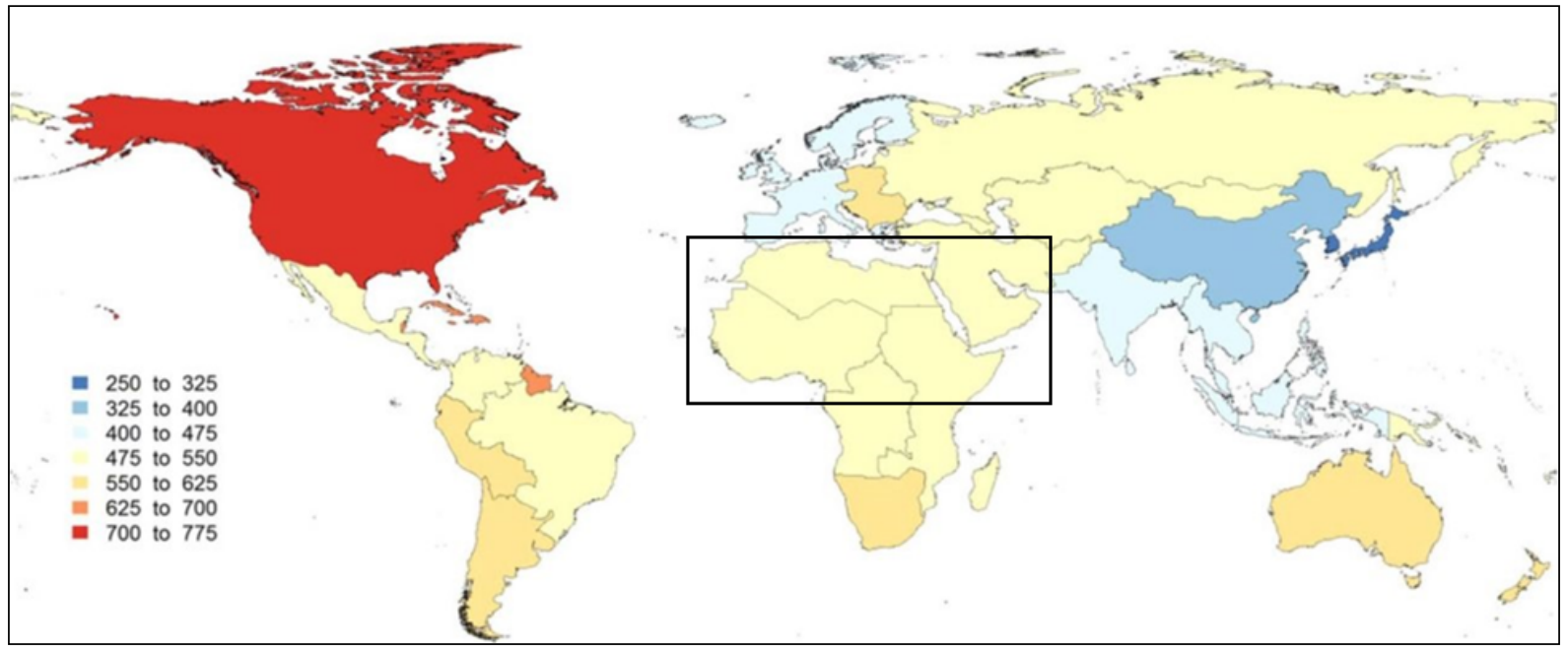

Figure 1. World map showing the age-adjusted prevalence rates (per 100000 population) of atrial fibrillation in the 21 Global Burden of Disease regions, 2010². ㄷ 2013 American Heart Association, Inc.

Atrial fibrillation (AF) is the most common form of arrhythmia with clinical significance and is a major global health burden. Silent or subclinical asymptomatic atrial fibrillation (SAF) has currently gained attention in the epidemiologic, neurologic and cardiovascular fields ${ }^{3}$. In addition, under treatment and poor follow-up in patients with AF might be an even larger problem than previously accounted for ${ }^{4}$.

There is proof of a progressive increase in overall burden, incidence, prevalence and AF associated mortality between 1990 and 2010 with significant public health implications. Thus, the disability-adjusted life years (DALY) increased by $18.8 \%$ in men and $18.9 \%$ in women and the mortality associated with AF increased by 2 -fold and 1.9-fold in men and women respectively ${ }^{2}$.

The worldwide age adjusted prevalence of AF, as estimated in the 2010 Global Burden of Disease study, is 596 per 100,000 men and 373 per 100,000 women, equating approximately 33 million people ${ }^{2}$. In the USA and European countries, it is estimated that 1 in every 4 middle-aged adults will likely develop AF ${ }^{5}$. Within the Arab world, AF burden varies greatly. For example, in 2017, the percentage of DALYs due to AF was over $0.17 \%$ in Tunisia, Bahrain and Lebanon, but less than $0.07 \%$ in Somalia, Sudan and Yemen ${ }^{6}$. In 2010, middle eastern countries recorded a moderate prevalence of AF and atrial flutter (475 till 550 cases per 100,000 inhabitants). Meanwhile, the United States recorded a high prevalence of AF (700 to 775 cases per 100,000 inhabitants) and China reported a low prevalence (250 to 325 cases per 100,000 inhabitants) (Fig. 1).

Studies in the Middle East are required to develop region-specific guidelines to ameliorate patient care ${ }^{7}$. Interest in public health in the Arab world has increased following the political and social changes faced by the Middle East since $2010^{8}$.

This study aims to evaluate the activity of AF related research in the Arab world. Articles published on AF in each of the 22 countries were collected from an online database according to the study location. This will help in raising awareness concerning $\mathrm{AF}$ and encouraging research on the topic. 


\section{METHODS}

This study is a bibliometric analysis, also called a scientometric study. This type of analysis seeks to measure publications, as well as citations and many other indexes ${ }^{9}$.

\section{Database and search strategy}

Articles were obtained from the MEDLINE database and are cited online on PUBMED. MEDLINE hosts, the largest database in biomedical research, thus justifying its usage in this study ${ }^{10}$. MEDLINE uses Medical Subheading $(\mathrm{MeSH})$ terms for searching articles; each article is assigned certain $\mathrm{MeSH}$ terms related to the subject ${ }^{11}$. Each MeSH term has its own code, and terms are organized in a MeSH tree. For example, when searching for "Arrhythmia" [MeSH term], it will also include articles on atrial fibrillation, heart block, Brugada syndrome and all other arrhythmias. Furthermore, all synonyms of a word are taken into consideration during the search. For example, when searching for "atrial fibrillation" [MeSH term] or "auricular fibrillation" [MeSH term], the same results will be obtained.

Boolean operators (and, or, not), as well as the affiliation of the author ([affiliation]), were used in this search to further indicate the country of publication and period of study. For example, for articles published in Yemen, the following was searched: ((“atrial fibrillation” [MeSH Terms]) AND ((“2004” [Date - Publication]: "2019” [Date - Publication]))) AND (Yemen [Affiliation]). The total number of articles related to arrhythmia was retrieved, in order to assess the contribution of atrial fibrillation among all arrhythmia publications. Concerning the number of publications from Lebanon, all publications originating in cities called "Lebanon" in the United States were excluded from this study. Moreover, in the case of Palestine, West Bank and Gaza strip affiliations were used to assess the number of papers.

\section{Analysis and comparison}

Articles published between 2004 and 2019 in all 22 Arab countries were included. Algeria, Bahrain, Comoros, Djibouti, Egypt, Iraq, Jordan, Kuwait, Lebanon, Libya, Mauritania, Morocco, Oman, Palestine, Qatar, Saudi Arabia, Somalia, Sudan, Syria, Tunisia, United Arab Emirates and Yemen were all screened for articles on AF.

However, the number of articles for each country is not sufficient for a standard comparison. Thus, it is crucial to standardize the number of publications by the following indicators: gross domestic product (GDP), DALYs and population size. The results may differ when different normalizing indicators are used ${ }^{12}$. The population for each country was retrieved from the 2019 World Population Prospect (WPP-2019) for the years 2004 to 2019, the GDP was obtained from the World Bank between 2004 and 2018, and DALYs of AF and atrial flutter were retrieved from the Global Burden of Diseases (GBD) between 2004 and 20176,13,14. Subsequently, the average population, average GDP and average DALYs were calculated and used to obtain the number of publications per million persons (PPMP), publications per GDP and publications per 1\% DALY. Linear regression, tabulated on SPSS (Statistical Package of Social Sciences) version 22, assessed the strength between the number of publications and the other quantitative variables (population, GDP and DALY).

In addition, in an effort to compare other regions' contribution in AF, the same search strategy was used to gather the number of publications in two main regions: Far East Asia and South America. This was done in order to assess the research contribution of AF in these regions compared to their total research activity and to the total AF research worldwide between 2004 and 2019. Far Eastern countries include China, Hong Kong, Macau, Japan, North Korea, South Korea, Mongolia, Siberia, Taiwan, Brunei, Cambodia, East Timor, Malaysia, Laos, Indonesia, Myanmar, Singapore, Philippines, Thailand and Vietnam. South American countries include Argentina, Bolivia, Brazil, Chile, Colombia, Ecuador, Guyana, Paraguay, Peru, Suriname, Uruguay and Venezuela. 


\section{RESULTS}

The average population size, average GDP (in USD billions) and average DALY related to AF for the 22 Arab countries are presented in (Table 1). From 2004 to 2019, researchers from Arab countries published 209,452 articles and only $0.13 \%$ of these publications addressed the problem of AF (Table 2). Additionally, 38,983 AF related articles were published worldwide, out of which $0.68 \%$ originated in Arab countries. Similarly, South America devoted only $0.13 \%$ of their research output for AF and contributed to $1.33 \%$ of the total research in AF worldwide. Far Eastern countries dedicated $0.22 \%$ of their total research to AF. However, they accounted for $15.68 \%$ of the total research activity related to AF worldwide.

Table 1. Average population, GDP (in USD billion) and percentage of AF related DALY for Arab countries (2004-2019).

\begin{tabular}{|c|c|c|c|}
\hline Country & Av. population & Av. GDP (billion \$) & Av. DALY (\%) \\
\hline Algeria & $37,359,438$ & 160.65 & 0.14 \\
\hline Bahrain & $1,249,091$ & 27.05 & 0.17 \\
\hline Comoros & 718,660 & 0.94 & 0.08 \\
\hline Djibouti & 866,421 & 1.59 & 0.05 \\
\hline Egypt & $86,266,141$ & 215.90 & 0.07 \\
\hline Iraq & $32,084,985$ & 151.16 & 0.08 \\
\hline Jordan & $7,885,521$ & 28.09 & 0.10 \\
\hline Kuwait & $3,234,030$ & 125.03 & 0.11 \\
\hline Lebanon & $5,626,327$ & 38.89 & 0.15 \\
\hline Libya & $6,245,227$ & 52.76 & 0.10 \\
\hline Mauritania & $3,683,546$ & 4.23 & 0.08 \\
\hline Morocco & $33,134,513$ & 91.13 & 0.11 \\
\hline Oman & $3,538,838$ & 59.49 & 0.10 \\
\hline Palestine* & $4,205,124$ & 9.64 & 0.09 \\
\hline Qatar & $1,962,132$ & 122.42 & 0.12 \\
\hline Saudi Arabia & $28,762,301$ & 569.45 & 0.09 \\
\hline Somalia & $12,636,382$ & $4.22^{* *}$ & 0.03 \\
\hline Sudan & $36,084,250$ & 63.26 & 0.04 \\
\hline Syria & $19,046,416$ & $31.92^{* \star \star}$ & 0.09 \\
\hline Tunisia & $10,812,039$ & 41.23 & 0.18 \\
\hline United Arab Emirates & $7,980,982$ & 312.86 & 0.05 \\
\hline Yemen & $24,224,626$ & 28.89 & 0.04 \\
\hline
\end{tabular}

*West Bank and Gaza. ${ }^{* *}$ Somalia data only available from 2013 to 2018. ${ }^{* * *}$ Syria data only available between 2004 and 2007

Five of the 22 Arab countries had no publications focusing on AF, including Comoros and Djibouti. The percentage of AF related articles to total published articles ranged from $0.02 \%$ in Algeria and Iraq to $0.44 \%$ in Qatar. Saudi Arabia ranked first in terms of number of AF publications with 56 publications between 2004 and 2019, followed by Egypt with 48 publications. Both Algeria and Iraq had the least publications in the same timeframe, with one publication each (Table 2).

After normalizing the numbers of publications according to population size, smaller countries like Qatar and Bahrain averaged a higher number of PPMP than larger Arab countries like Egypt and Saudi Arabia. Qatar had the highest PPMP with 20.39 PPMP between 2004 and 2019, followed by Bahrain with 4.80 publications (Fig. 2). 
Table 2. Number of AF publications, total publications and percentage of AF publications to total publications for the Arab countries (2004-2019).

\begin{tabular}{|c|c|c|c|}
\hline Country & Publications & Total publications & $\%$ of total \\
\hline Algeria & 1 & 4,345 & 0.02 \\
\hline Bahrain & 6 & 1,582 & 0.38 \\
\hline Comoros & - & 42 & - \\
\hline Djibouti & - & 101 & - \\
\hline Egypt & 48 & 57,976 & 0.08 \\
\hline Iraq & 1 & 4,885 & 0.02 \\
\hline Jordan & 6 & 11,841 & 0.05 \\
\hline Kuwait & 11 & 6,071 & 0.18 \\
\hline Lebanon & 25 & 11,709 & 0.21 \\
\hline Libya & 1 & 1,047 & 0.10 \\
\hline Mauritania & - & 120 & - \\
\hline Morocco & 3 & 8,085 & 0.04 \\
\hline Oman & 12 & 5,201 & 0.23 \\
\hline Palestine* & - & 1,126 & - \\
\hline Qatar & 40 & 9,168 & 0.44 \\
\hline Saudi Arabia & 56 & 56,357 & 0.10 \\
\hline Somalia & - & 111 & - \\
\hline Sudan & 4 & 3,295 & 0.12 \\
\hline Syria & 4 & 1,438 & 0.28 \\
\hline Tunisia & 16 & 15,505 & 0.10 \\
\hline United Arab Emirates & 27 & 8,176 & 0.33 \\
\hline Yemen & 4 & 1,271 & 0.31 \\
\hline Total & 265 & 209,452 & 0.13 \\
\hline
\end{tabular}

${ }^{*}$ West Bank and Gaza.

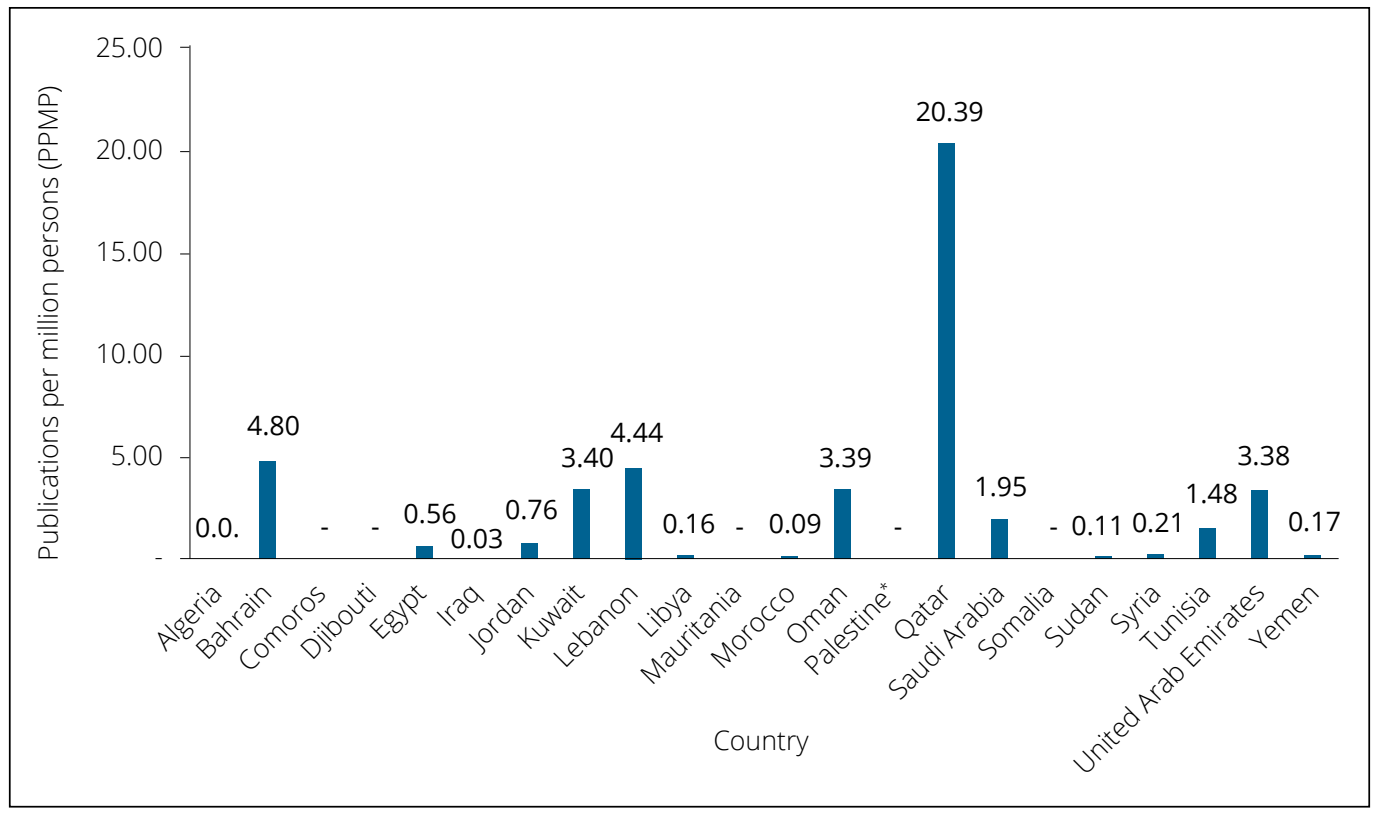

Figure 2. Atrial fibrillation PPMP values for the Arab countries (2004-2019).

* West Bank and Gaza. 
Furthermore, the number of publications can be normalized by dividing the number of AF publications by the average GDP (in USD billions) for each country. The GDP is a widely used measure to assess and compare national economies ${ }^{15}$. Lebanon surpassed the remaining Arab countries, averaging 0.64 publications per USD billion GDP, followed by Tunisia with 0.39 publications. Algeria and Iraq registered the lowest number of publications per USD billion GDP with 0.01 publications each (Fig. 3).

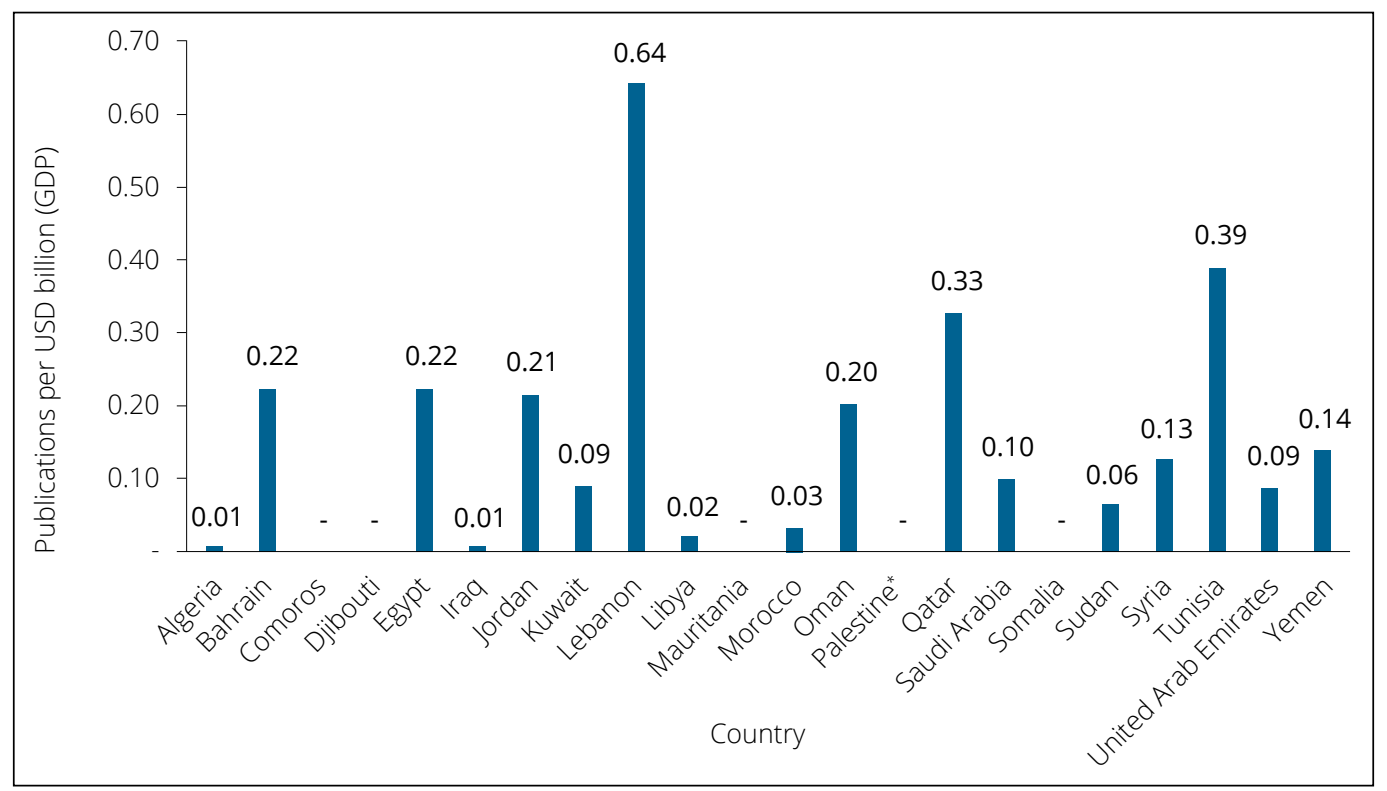

Figure 3. Atrial fibrillation publications per GDP (in USD billions) for the Arab countries (2004-2019). * West Bank and Gaza.

Atrial fibrillation related DALYs showed to be relatively low in all Arab countries, ranging from $0.03 \%$ in Somalia to $0.18 \%$ in Tunisia. Generally, the higher the percentage of DALY for a specific disease, the more researchers are expected to be interested and engaged in research work addressing the disease. According to the number of publications per 1\% DALY related to AF, Egypt had the highest value with 646.60 publications, followed by Saudi Arabia with 630.77 publications. Libya and Algeria presented the lowest numbers of publications per 1\% DALY, averaging 10.03 and 7.11, respectively (Fig. 4).

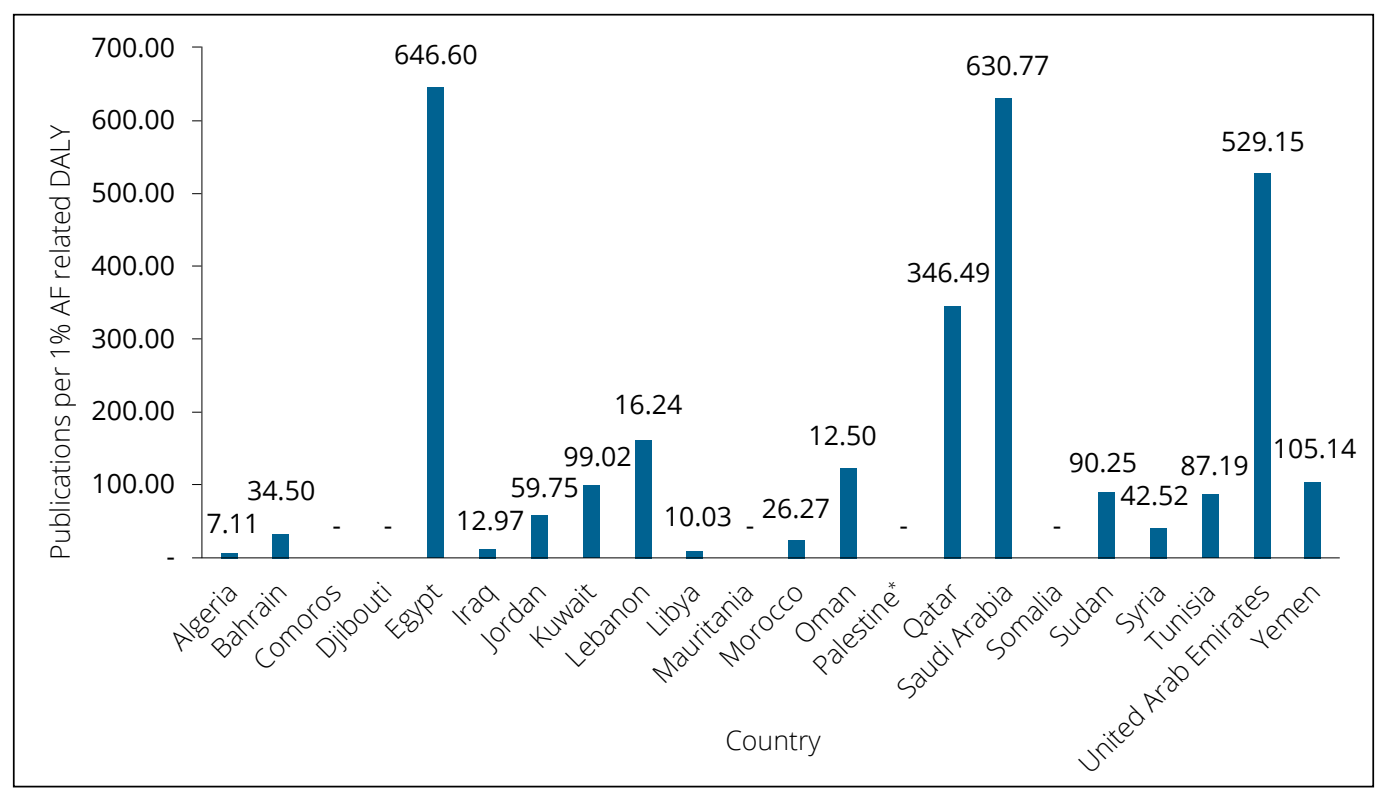

Figure 4. Atrial fibrillation publications per 1\% AF related DALY for the Arab countries (2004-2019). * West Bank and Gaza. 
Linear regression indicated that the number of AF related publications was positive, significantly and strongly correlated with the average country GDP (in USD billions, $r=0.757, p<0.001$ ). Moreover, nonsignificant, positive and weaker correlations were found between the number of publications and the average population size $(r=0.36, p=0.096)$ and between the number of publications and the average percentage of DALY related to AF $(r=0.11, p=0.618)$.

\section{DISCUSSION}

Even though a substantial increase in the number of publications related to AF is noticed in the Arab world (Fig. 5), it is still low when compared to other countries. In fact, the Arab world contributed to only $0.68 \%$ of AF related articles published between 2004 and 2019, while AF related research accounted for only 0.13\% of total publications in the Arab world (Table 2).

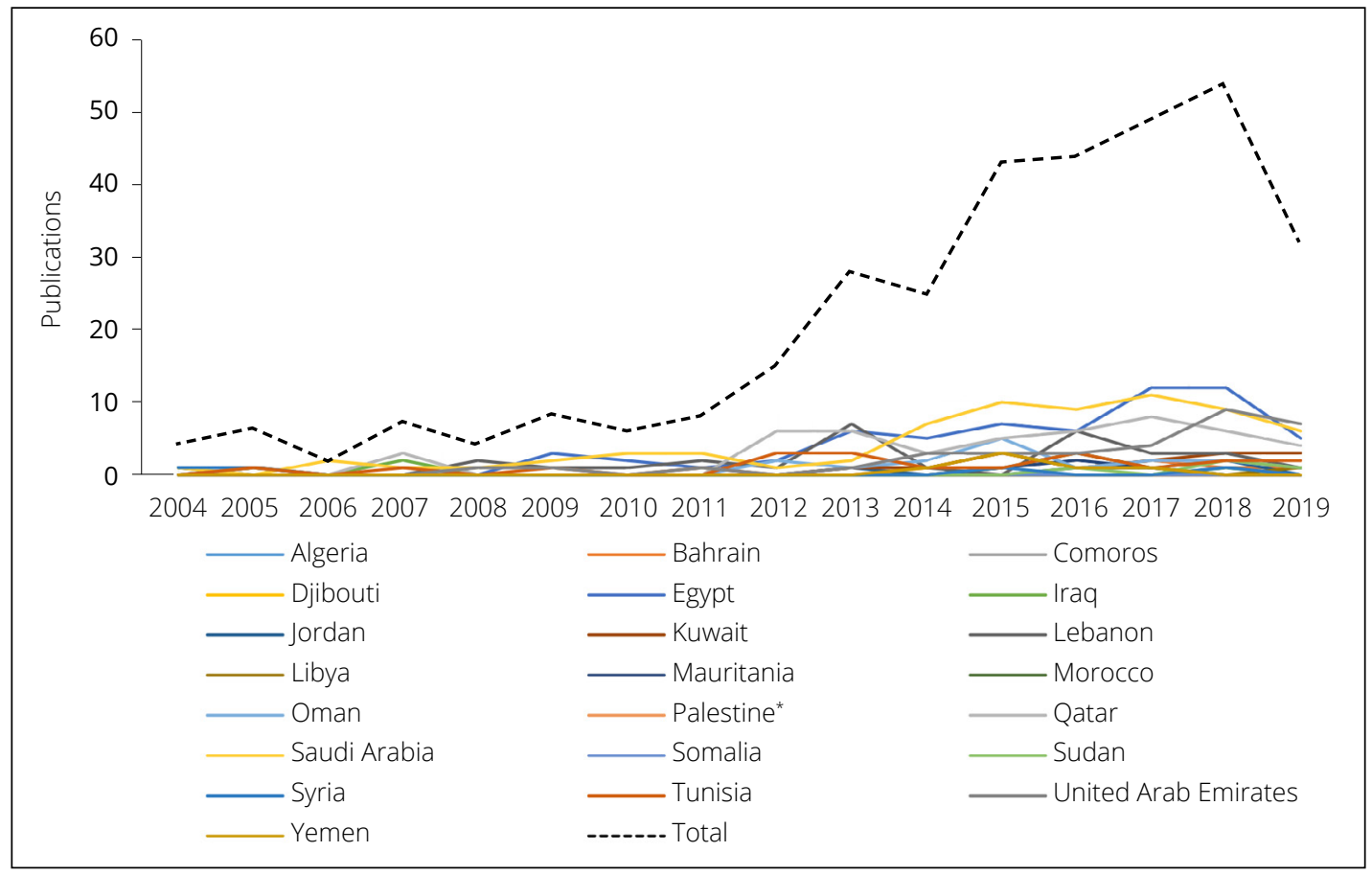

Figure 5. Number of AF publications in Arab countries from 2004 to 2019.

* West Bank and Gaza.

\section{Analysis of the normalized data}

Even though Saudi Arabia ranked first in terms of number of AF publications, followed by Egypt (Table 2), these numbers could not be representative. Lebanon is the country with the highest number of publications per USD billion GDP (Fig. 3), while Egypt and Saudi Arabia rank first when normalizing to the number of publications per 1\% DALY (Fig. 4). Finally, Qatar and Bahrain produced the highest number of PPMP (Fig. 2). A strong and positive correlation was found between the number of publications and the GDP $(r=0.69)$. The population size $(r=0.31)$ and the percentage of $\operatorname{DALY}(r=0.18)$ showed positive yet weak correlation.

\section{Research activity in the Arab world}

Despite the increase of AF publications observed in recent years (Fig. 5), AF related research is still insufficient in the Arab world. Arab countries contributed with $0.68 \%$ of the total research in AF, while the Far East and South America had significantly higher contributions in this area of research (15.68 and 1.33\%, respectively). In a matter of fact, clinical management of patients with AF in the Arab world is based on guidelines elaborated exclusively by western studies. High 
quality epidemiological studies and clinical trials performed for AF in the Middle East seem to be rare ${ }^{8}$, and the Arab world is releasing fewer biomedical publications that are of lower quality in comparison to other Middle Eastern countries ${ }^{16}$. For these reasons, studies are needed to identify the causes and to propose strategies to improve the quantity and the quality of research in Arab countries. Political instability, regional conflicts, lack of proper research infrastructure and equipment, lack of freedom and democracy, brain drain, lack of funding and difficulty of publishing in high impact journals seem to be the main reasons for the lack of research ${ }^{17}$. Moreover, ethical issues are being raised in the Arab world, including serious misconduct in medical research and practice and biased funding and recruitment policies called "wasta" (meaning "intercession") ${ }^{18}$.

Given the fact that most research works need funding, one of the key issues facing the Middle East is the economic and social impact of wars and conflicts, as well as the lack of data and research output during these unstable periods. For example, the Syrian war spillover on neighboring countries, such as Lebanon, affected its GDP, increasing only by $0.2 \%$ in 2018, compared to $0.6 \%$ in $2017^{19}$. This is also the case of the Arabian Peninsula, where the Yemen civil war is taking place since 2015. Furthermore, research shifted its focus on COVID-19 and its economic impact, not only in the Arab countries, but also worldwide. All these factors reflect negatively on the future of research in the Arab world, especially on cardiovascular diseases.

\section{Atrial fibrillation and other arrhythmias related research activity}

Despite AF being the most common type of arrhythmia ${ }^{20}$ and despite its continuous increase in incidence ${ }^{21}$, only $35.86 \%$ of arrhythmia related articles discussed AF in the Arab world (Table 3).

Moreover, out of 1,032,862 articles related to cardiovascular diseases published worldwide from 2002 to 2016, 1\% originated in the Arab world1. Meanwhile, out of $38,983 \mathrm{AF}$ related articles published worldwide, only $0.73 \%$ originated in the Arab world. This shows how much other nations favor AF related research over other cardiovascular diseases, compared to the Arab world. Most articles emphasized on the mechanism and treatment of $\mathrm{AF}^{22}$.

Table 3. Classification of arrhythmia related publications in Arab countries (2004-2019).

\begin{tabular}{|c|c|c|c|}
\hline Country & $\mathrm{AF}$ & non-AF & All arrhythmia \\
\hline Algeria & 1 & 12 & 13 \\
\hline Bahrain & 6 & 6 & 12 \\
\hline Comoros & - & - & - \\
\hline Djibouti & - & 1 & 1 \\
\hline Egypt & 48 & 88 & 136 \\
\hline Iraq & 1 & 9 & 10 \\
\hline Jordan & 6 & 20 & 26 \\
\hline Kuwait & 11 & 13 & 24 \\
\hline Lebanon & 25 & 56 & 81 \\
\hline Libya & 1 & - & 1 \\
\hline Mauritania & - & - & - \\
\hline Morocco & 3 & 15 & 18 \\
\hline Oman & 12 & 12 & 24 \\
\hline Palestine* & - & - & - \\
\hline Qatar & 40 & 42 & 82 \\
\hline Saudi Arabia & 56 & 152 & 208 \\
\hline Somalia & - & & - \\
\hline Sudan & 4 & 3 & 7 \\
\hline Syria & 4 & 2 & 6 \\
\hline Tunisia & 16 & 24 & 40 \\
\hline United Arab Emirates & 27 & 29 & 56 \\
\hline Yemen & 4 & 1 & 5 \\
\hline
\end{tabular}

*West Bank and Gaza. 


\section{Lack of diagnosis and increase in incidence}

Silent atrial fibrillation $(\mathrm{SAF})$ is underdiagnosed worldwide ${ }^{23}$. Advanced tools showing some promising results are being used to diagnose SAF. However, the Arab world is facing financial limitations that may hinder their accessibility. Another problem was pointed out by Al-Shamkhani et al. ${ }^{7}$ when they proved that patients with high AF risk in the Middle East are undertreated, if not left untreated, leading to an increased risk of complications (stroke and heart failure).

Interestingly, Habibzadeh ${ }^{24}$ showed that the prevalence of AF triples each decade in the Middle East, while it only doubles in the USA. Part of this considerable increase might be due to a decrease in physical activity in the Middle East ${ }^{25}$ and a sedentary lifestyle, knowing that the lack of physical activity increases the risk of $\mathrm{AF}^{26}$.

\section{Need for collaboration}

In addition to the lack of AF related research (Table 3) due to many reasons previously discussed, a collaboration between science and media is of crucial importance to promote a healthier lifestyle in the Arab world. This is important because living a healthy lifestyle reduces the incidence of $\mathrm{AF}$ and improves the outcome of $\mathrm{AF}$ patients $\mathrm{s}^{27,28}$.

\section{Limitations}

Only one database was used, the MEDLINE database (which is cited online on PUBMED) to obtain the published articles. This might have caused an underestimation of the total number of AF publications released by each country and consequently by the Arab world as a whole. In addition, the results were analyzed while considering that all publications have the same importance, since there are no common criteria that classify the publications by their importance, number of citations, type or size.

\section{CONCLUSIONS}

This is the first bibliometric analysis done to describe medical research productivity on AF in the 22 Arab countries from 2004 to 2019. Despite the increasing numbers of AF cases over this period, the total number of publications addressing this problem over the past 15 years has only slightly increased in the Arab countries compared to the remaining regions of the world. This gap is further aggravated by the prevalent political system that does not prioritize scientific research. Therefore, there is an urgent need for studies in the Arab world in order to get a better understanding of widespread diseases, as well as establish adequate plans of action.

\section{ACKNOWLEDGMENTS}

Not applicable.

\section{FUNDING}

This work did not receive any funding.

\section{AUTHORS' CONTRIBUTION}

Conceptualization: El Hage S. and Akiki D.; Methodology: Salemeh P., Wakim E., El Hage S. and Safi S.; Original Draft: Akiki D., Wakim E., El Hage S. and Safi S.; Review and Editing: Assouad E. and Salemeh P.; Resources: El Hage S. and Safi S. 


\section{REFERENCES}

1. Khachfe HH, Refaat MM. Bibliometric analysis of Cardiovascular Disease Research Activity in the Arab World. International Cardiovascular Forum Journal. 2019;15:25-8. https://doi.org/10.17987/icfj.v15i0.554

2. Chugh SS, Havmoeller R, Narayanan K, Singh D, Rienstra M, Benjamin EJ, et al. Worldwide Epidemiology of Atrial Fibrillation: A Global Burden of Disease 2010 Study. Circulation. 2014;129(8):837-47. https://doi.org/10.1161/CIRCULATIONAHA.113.005119

3. Dilaveris PE, Kennedy HL. Silent atrial fibrillation: epidemiology, diagnosis, and clinical impact. Clin Cardiol. 2017;40(6):413-8. https:// doi.org/10.1002/clc.22667

4. Rahman F, Kwan GF, Benjamin EJ. Global epidemiology of atrial fibrillation. Nat Rev Cardiol. 2014;11:639-54. https://doi.org/10.1038/ nrcardio.2014.118

5. Zulkifly H, Lip GYH, Lane DA. Epidemiology of atrial fibrillation. Int J Clin Pract. 2018;72(3):e13070. https://doi.org/10.1111/ijcp.13070

6. Global Burden of Disease Collaborative Network. Global Burden of Disease Study 2017 (GBD 2017) Results. Seattle, United States: Institute for Health Metrics and Evaluation (IHME), 2018. [cited Jun 14 2020] Available at: http://ghdx.healthdata.org/gbd-2017

7. Al-Shamkhani W, Ayetey H, Lip GYH. Atrial fibrillation in the Middle East: unmapped, underdiagnosed, undertreated. Expert Rev Cardiovasc Ther. 2018;16(5):341-8. https://doi.org/10.1080/14779072.2018.1457953

8. Blair I, Grivna M, Sharif AA. The "Arab World" is not a useful concept when addressing challenges to public health, public health education, and research in the Middle East. Front Public Health. 2014;2:30. https://doi.org/10.3389/fpubh.2014.00030

9. Osareh F. Bibliometrics, Citation Analysis and Co-Citation Analysis: A Review of Literature I. Libri. 1996;46(3):149-58. https://doi. org/10.1515/libr.1996.46.3.149

10. Masic I, Milinovic K. On-line biomedical databases-the best source for quick search of the scientific information in the biomedicine. Acta Inform Med. 2012;20(2):72-84. https://doi.org/10.5455/aim.2012.20.72-84

11. Baumann N. How to use the medical subject headings (MeSH). Int J Clin Pract. 2016;70(2):171-4. https://doi.org/10.1111/ijcp.12767

12. Shaban SF, Abu-Zidan FM. A quantitative analysis of medical publications from Arab countries. Saudi Med J. 2003;24(3):294-6.

13. World Bank national accounts data, and OECD National Accounts data files. GDP (current US\$). The World Bank. [cited May 12 2020]. Available at: https://data.worldbank.org/indicator/NY.GDP.MKTP.CD

14. World Population Prospects 2019. Department of Economic and Social Affairs Population Dynamics. United Nations. [cited May 12 2020]. Available at: https://population.un.org/wpp/

15. Cheng E, Cao L. Establishing the "Gross Domestic Product of Welfare": A Major Revision of GDP for a Better Accounting System. World Rev Polit Econ. 2014;5(4):439-54. https://doi.org/10.13169/worlrevipoliecon.5.4.0439

16. Benamer HTS, Bakoush O. Arab nations lagging behind other Middle Eastern countries in biomedical research: a comparative study. Med Res Methodol. 2009;9:26. https://doi.org/10.1186/1471-2288-9-26

17. El Rassi R, Meho LI, Nahlawi A, Salameh JS, Bazarbachi A, Akl EA. Medical research productivity in the Arab countries: $2007-2016$ bibliometric analysis. J Glob Health. 2018;8(2):020411. https://doi.org/10.7189/jogh.08.020411

18. Moustafa K. Promoting an academic culture in the Arab world. Avicenna J Med. 2018;8(3):120-23. https://doi.org/10.4103/ajm. AJM_166_17

19. Lebanon Overview. The World Bank in Lebanon. [cited June 13 2020]. Available at: https://www.worldbank.org/en/country/lebanon/ overview

20. Wyndham CR. Atrial fibrillation: the most common arrhythmia. Tex Heart Inst J. 2000;27(3):257-67.

21. Conen D. (2018). Epidemiology of atrial fibrillation. Eur Heart J. 2018;39(16):1323-24. https://doi.org/10.1093/eurheartj/ehy171

22. Prystowsky EN. The History of Atrial Fibrillation: The Last 100 Years. J Cardiovasc Electrophysiol. 2008;19(6):575-82. https://doi. org/10.1111/j.1540-8167.2008.01184.x

23. Barbarossa A, Guerra F, Capucci A. Silent Atrial Fibrillation: A Critical Review. J Atr Fibrillation. 2014;7(3):1138.

24. Habibzadeh Farrokh. Atrial fibrillation in the Middle East. Lancet. 2008;379. 
25. Sharara E, Akik C, Ghattas H, Obermeyer CM. Physical inactivity, gender and culture in Arab countries: a systematic assessment of the literature. BMC Public Health. 2018;18(1):639. https://doi.org/10.1186/s12889-018-5472-z

26. Nielsen JR, Wachtell K, Abdulla J. The Relationship Between Physical Activity and Risk of Atrial Fibrillation-A Systematic Review and Meta-Analysis. J Atr Fibrillation. 2013;5(5):789.

27. Sabzwari SRA, Garg L, Lakkireddy D, DayJ. Ten Lifestyle Modification Approaches to Treat Atrial Fibrillation. Cureus. $2018 ; 10(5): e 2682$. https://doi.org/10.7759/cureus.2682

28. Middeldorp ME, Ariyaratnam J, Lau D, Sanders, P. Lifestyle modifications for treatment of atrial fibrillation. Heart. 2020;106(5):32532. https://doi.org/10.1136/heartjnl-2019-315327 